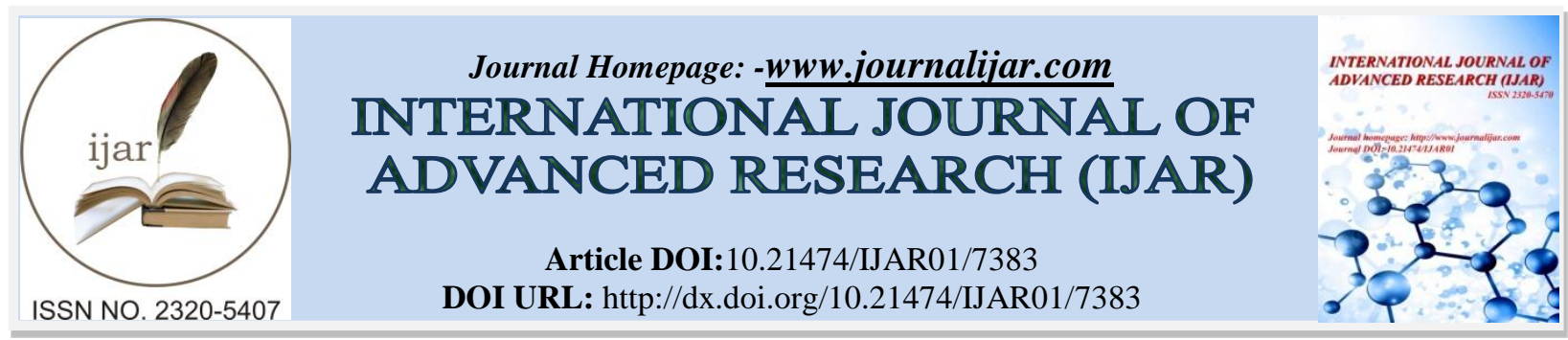

RESEARCH ARTICLE

\title{
EVALUATING THE EFFECTIVENESS OF THE UNITED NATIONS ORGANIZATIONS: THE LIMITS OF THEORIES AND NEED FOR A 'NEW ANALYTICAL FRAMEWORK'.
}

Sarwar J. Minar.

Senior Officer, International Programs and Relations, Independent University, Bangladesh.

\section{Manuscript Info}

Manuscript History

Received: 10 May 2018

Final Accepted: 12 June 2018

Published: July 2018

\section{Abstract}

The article evaluates the effectiveness of the United National Organizations (UNO). The article overviews the argument put forth both by the liberalist tradition that posits UNO is an effective international organization and by the realist tradition that posits UNO to be an ineffective international organization. The article, therefore, argues for 'need of a new analytical framework' to better understand and evaluate the success and/or failure of the UNO in the $21^{\text {st }}$ century and beyond.

Copy Right, IJAR, 2018,. All rights reserved.

\section{Prologue:-}

In the post-WWII era states of the world came together to establish a common international organization to stop breaking out of any more major conflict and to establish world peace. Therefore, they established the United Nations Organization (UNO). States of the world came together under the leadership of the then major powers of the world, to establish and maintain collective international peace and security, protect international law, protect and promote human rights worldwide, address international environmental concerns and to deal with fundamental threats to international security (Dunne, 2007: 103) (Hanhimäki, 2008:1). The core principles of the UNO are laid out in its Charter, which comprises a complex set of rules for the proper functioning of the UNO within an international framework to bring about the peace and harmony that the member states craved for so long. The United Nations is supportive of "democratic governments, economic interdependence" and "as means to overcome the security dilemma of the international system" (Dunne, Tim, Kurki, Milja and Smith, Steve 2010:96).

However, the effectiveness of the UNO has become a topic of moot as UNO was successful to resolve some issues and unsuccessful to resolve some others. The function of the United Nations in the international milieu seems to become more and more controversial day by day and its effectiveness is being constantly put under 'question'. The realist tradition, one the one hand, posits a pessimistic assessment about the effectiveness of the UNO and argues that UNO is an ineffective institution. The liberalist tradition, on the other hand, posits an optimistic assessment about the effectiveness of the UNO and argues that UNO is an effective institution. While both schools of thought present logical and different assessment, this essay argues both school's arguments are inadequate and therefore misleading to evaluate overall effectiveness of the UNO.

This paper proposes a 'new approach' to the evaluation of the effectiveness of the United Nations Organization that the evaluation of the effectiveness of the UNO must be case or issue specific. That is whether UNO is effective or ineffective with reference to a particular case or issue. On the contrary, this paper argues that it would be misleading to conclude based on one single aspect of the UNO or one single case that the whole UNO is effective or ineffective institution. 
First this paper will address briefly why UNO is considered as an effective institution and then this paper will address why UNO is considered as an ineffective institution. Then this paper will present a 'new approach' to the evaluation of the effectiveness of the UNO and give rationales why this new approach is better to the evaluation of the UNO.

Why is UNO considered to be an Effective Organization?:-

The liberalist tradition posits an optimistic view about the effectiveness of the UNO. The liberal school of thought believes that international security and order can develop out of an international organization and that belief initially led to the creation of the UN. Being strongly influenced by Immanuel Kant, this school argues that "wellfunctioning international organizations contribute to the formation of peace" (Kantian project in IR, 2004). Roughly around $85 \%$ of the members of the UNO ratified the International Covenant on Civil and Political Rights (United Nations, 2012) and that signifies UNO's strength in converging interests of the states of the world. Kant in his Democratic Peace Theory further argued that it is highly unlikely that democracies go to war with each other which is highly conducive to create world peace in the long run. Chapter II of the UN Charter outlines, "membership in the UN is open to all other peace-loving states" (United Nations, 1945) and that signifies the universal character of the UNO.

UNO has successfully adopted the nuclear proliferation treaty (NPT) that aims to limit the spread of nuclear weapons, and is a good "expression of the practices of international law and multilateralism in the field of arms control" (Baylis \& Smith, 2011:281). Once a resolution is passed by UNO it is considered to be important to all member states that all member-states of the UNO abide by the resolution. Liberals claim that "after the Cold War it became more difficult for states and diplomats to accept that what happened within states was of no concern to outsiders" (Baylis, 2011: 318). As a result, the UNO became more involved in the mediation between nations, which granted it higher respect from member states. "By the mid-1990s the UNO had become involved in maintaining international security by resisting aggression between states" (Baylis, 2011: 318). Liberalists including Kofi Annan argued that the 'security dilemma', which is built on the premise that "one country improves its security at the expense of other states" (Dunne, 2010: 81) had been averted. The recent past has been bright in terms of the UNO serving as a successful platform for peace and compromise between states. The success stories of the UNO peacekeeping missions around the world are very well known and praised globally. The UNO's peacekeeping operations have been successful to a large extent that include the UN Transition Assistance group (UNTAG) in Namibia, UN Observer Group in Central America (ONUCA) as well as the UN Iraq-Iran Military Observer Group (UNIIMOG) since 1948 up to 2014, some of which are still active. These peace operations are considered to play a key role in the maintaining of international peace and security. Liberalists have the upper hand in rejoicing UN success rates in areas of civil conflict; "Namibia (1989-90), El Salvador (1991-95) and Cambodia (1991-93) are repeatedly cited as success stories" (Weiss 2007: 104-5). In addition, the presence of peacekeeping forces "are involved in the democratization processes" (Ritterberger, 2006: 134). Kant claims that one of the objectives of international organizations such as the UN is to democratize single party countries. Peacekeeping operations are also argued to have positive impact in improving civil-military relations in developing states, for example in Bangladesh (Zaman \& Biswas, 2014).

The UNO has been praiseworthy concerning its health efforts around the world. The World Health Organization (WHO) is a branch of the UN which helps promote health and development in areas of extreme poverty and conflict around the world. These 'branches' reinforce Kant's liberalist theory that international institutions are effective tools in solving health problems and preventing conflict. George Gibbs, an American ethnologist, asserted that the agenda of the WHO interferes too much with the legislations of sovereign states (WHO Profile, 2008). However, the success of UNO regarding health is undoubting, "critics and supporters alike celebrate the eradication of smallpox; in this the WHO has made a big difference in the world" (WHO Profile, 2008). Through the process of democratization UNO helps countries to benefit in areas like health and human rights and this also helps to prevent further conflict and human suffering. It is obvious that the 'UNO, via organizations including the WHO, UNTAG, ONUCA and UNIIMOG have provided general healthcare and peacekeeping efforts effectively'. These reflect Immanuel Kant's liberalist theory that international institutions promote positive results in countries in need of aid and mediation. Thus, the UNO has been an effective institution in establishing peace and promoting health-care efforts throughout the world. 
Identically, the UNO has been meaningfully effective in addressing other concerns of the world, for instance, climate change, environmental concerns and implementing humanitarian rights around the world etc. The UNO has been successful in raising awareness and legislating environmental practices in many of its member states. The alarming nature of climate change has been addressed by the UN through the creation of the Environmental Programme in 1972, followed by the introduction of an Environmental Committee. UNO's response to environmental concerns strongly backs the idea of liberalism that "liberal societies have become a fertile ground for the promotion of ecological attitudes and environmental philosophy" (De Shalit, 1995: 49). The evidence illustrated by the Rio Summit, Montreal and Kyoto Protocol's (UNEP, 2012) suggest that the UNO has been effective in recognizing and fighting environmental problems such as deforestation and climate change. Additionally, the UNO has substantially contributed to the promotion of humanitarian rights worldwide. Article 1 of UNO charter reads that it "promotes and encourages respect for human rights and for fundamental freedoms for all without discrimination as to race, sex, language or religion" (UN Charter, 2012). For the past century many liberals have strongly endorsed human rights as the best mechanism for providing a life of autonomy (Baylis, 2011: 505). Through the UNO, liberalists have enjoyed equality across all cultures. However, the UNO's Human Rights Council has been a highly influential means in promoting issues such as homosexuality, torture rights as well as women rights and child rights throughout the world. As a result, massive liberalization even in developed countries like the UK, France, and the USA etc. has been witnessed. They embraced liberal approaches to humanitarian issues discussed in the UNO. Due to such level of extraordinary and successful collaboration, the UNO has been an effective institution in promoting legislation of environmental and humanitarian rights laws around the world. Thus, the liberalists argue that the UNO should be considered to be an effective international organization in the world stage.

Why is UNO considered to be an Ineffective Organization?:-

The realist tradition posits a pessimistic view about the effectiveness of the UNO. This school of thought focusing on national state as dominant actor in world stage and power politics, argues that international institutions can help little in channeling the perpetual power struggle between states because they cannot change the anarchical structure of the international system (Rittberger, 2006: 15). Moreover, the UNO consists of a high number of diverse ideologies around the world which some scholars believe to be the cause for different positions and approaches on how to approach, govern and even to intervene in the same case of issue. Some believe that this results in ineffective procedures of the UNO.

Ensuring 'collective security' was a top priority of the states in the UNO's agenda in the post-World War II era. But the UNO was unable to prevent a series of conflicts that broke out in the period since 1945 to till date especially from 1945 to 1990 . The realists may argue that the "logic of collective security is contrasted with the difficulties of its application" (Weiss, 2007: 4) but it is sure that the UNO failed to take necessary and required steps. It is obvious that there was a hefty sense of distrust after the Second World War among the then world powers which is highlighted by the Security Council's 193 vetoes between 1945-1990" (Baylis, 2011: 316). The United States' invasions of Vietnam, Grenada and Panama in addition to the Soviet Union's invasions of Hungary, Czechoslovakia and Afghanistan (Weiss, 2007: 4) are a few instances of the constantly prevailed proxy war operations conducted throughout the second half of the $20^{\text {th }}$ century that seriously undermined UNO's effectiveness and virtually proved that "there is no supranational authority (i.e., the UNO) capable of wielding overwhelming power" (Rittberger, 2006: 15) as the realists suggest.

The realist tradition further adds that the "international organizations are used by powerful states to implement their power politics more effectively and to pursue their self-interest" (Rittberger, 2006: 15). When evaluating the case studies of Rwanda and Sierra Leone (Weiss, 2007: 206) realists argue that the actual reason why the UN was not as effective is largely due to the fact that Rwanda had little interest to the hegemonic powers at that time. Other conflicts, however, such as the Korean War, had strong backing from countries such as the US, UK and other nations in Europe, because it was in their interests to do so. This reveals the great powers' influence over the UNO to make the UNO to engage selectively. In Korea's case, the UN was effective in restoring security. But this largely contradicts Kant's claim that "international organizations can constrain decision-makers by positively promoting peace" (Dunne, 2010: 102). From the evidence illustrated it can be deducted that hegemonic states have superior influence over those of the UNO. Therefore, it is barely surprising that the UNO succeeded in restoring security when it was in the general interest of the unipolar state at that time (i.e., the USA), rather than the concern of the majority of the states sitting in the General Assembly. 
The very organization of the Security Council clearly reflects the great power politics. As World War II came to an end, the conquerors Russia, China, the United States, Great Britain and France who took steps to establish an international organization were granted permanent membership in the Security Council of the UNO and were awarded individual 'veto powers' over all UNO proposals and no democratic vote took place over that. The permanent members, each of the Great Powers turn into powerful agents within the UNO in the international affairs as they could block decisions that they think go against their national interests. Thus, if the UNO remains dependent on the opinions of these agents then the organization becomes a socially-constructed process that would make the position of the Security Council a realist one, destining the Security Council to be undemocratic and therefore ineffective organization (Burchill, 2005:150). For instance, the Syrian crisis can be said to be a result of the vetoes from Russia and China at the Security Council in July of 2012 "to block robust UN action to stop the massacres" (The Economist, 2012). They ostensibly did so to pursuit their self-interest, as they fear the democratic movements behind the latest happenings across Africa and the Middle East might shift the power balance and allegiances in their respective regions. This clearly illustrates that Security Council resolutions are still outcome of power politics and "one cannot realistically expect the UNO to solve issues in which the vital interests of one or more of the major powers are involved" (Kay, 1977:5). The freedom of the nations in the UNO to debate any pressing issue has essentially lead to the agencies to become "politicized", meaning that the controversial issues that might not be relevant to the agencies' work are introduced by member-states to further their political interests, altering agenda formation (Kay, 1977-80-86). Comparatively smaller or poorer nations would therefore be less likely to be able to put importance and prioritize their issues, as Great Powers neglect their security concerns. Thus, the UNO itself becomes an anarchic ground where states attempt to keep the balance of power in their favor, even though it is contradictory to the doctrine of sovereign equality.

In addition, the non-compliance of the states with UNO resolutions is also noteworthy. States keep prioritizing their own policies and do not comply with UNO's resolutions and treaties. Non-proliferation treaty is not wholly successful because of many states' non-compliance. The United States and many other states that signed the treaty still possess and/or continue developing nuclear weapons. This holds the realist assumptions that states prioritize their own security over concern of collective security. The current nuclear situation and disagreement between the United States and Iran also reflects this. The hegemonic USA wants to make use of the NPT and forbid Iran to possess nuclear weapons and see the actions of Iran as an offense. At the same time, they are unwilling to lose their own weapons. This illustrates how ineffective the treaties of the UNO can be. Though Kyoto protocol has been initiated by the UNO, the realists heavily criticize such collective attempt to prevent environmental problem. The aim of the critical research is to highlight how scientific explanations of environmental chance provide only partial insights into complex processes, and existing models of explanation that reflect the agendas of the societies that created them (Kim, 2001: 146). Profound economic powerhouses such as the USA, (the only nation to not attend the conference) found that it was not in their interest to curb production at the expense of the environment. This approach strongly emphasizes a realist attitude.

Moreover, there is also disagreement about the scope of the UNO and its policy. Critics argue that the United Nations became increasingly distant from 'We, the people', being more government-led institute (Thakur 1998:1). This claim is backed up by the fact that there are "countries like India, Indonesia, Nigeria, South Africa and Brazil" which "are important middle and regional powers", but which are not taken into consideration for a place in the Security Council, regardless of the loyalty shown towards the organization (Thakur 1998:10). This is mainly because the five states which possess permanent membership have powerful governments, and are therefore highly unlikely to be unseated. With regards to peace-keeping, despite huge success, the realists argue that "the network of international organizations is spread very unevenly across the globe" (Dunne, 2010: 104). Most realist thinkers "draws our attention to the fact that states are principally concerned with the national interest" (Baylis, 2011: 506) and often humanitarian values have become no more important than environmental or economic interests. The neorealists argue that the international system is anarchic in which states prioritize their own survival and security strategy over UNO and that ultimately hinders the UN from effective decision-making and development.

John Mearsheimer argued, "States are often reluctant to enter into cooperative agreements for fear that the other side will cheat on the agreement and gain a relative advantage" (Mearsheimer, 1994:13). According to realists, with survival being the main thought of the member states of the UNO, the states would choose absolute gains over relative gains. As Grieco points out, "A state will focus both on its absolute and relative gains from cooperation, and a state that is satisfied with a partner's compliance in a joint arrangement might nevertheless exit from it because the partner is achieving relatively greater gains" (Grieco, 1988:8). This inhibits the states from cooperation even when 
they would share common interests, reducing the capabilities of the UNO and making it ineffective. Thus, the realists argue that the UNO should be considered as an ineffective organization in the world stage.

\section{Evaluating the Effectiveness of the UNO: The Limit of Theories:-}

While the arguments of the both realist tradition and liberalist tradition remains precise and bonafide in many aspects their explanations, especially conclusion is inadequate to understand the overall effectiveness of the UNO. Explanation offered by each school regarding the effectiveness of the UNO leaves out essentially important aspect or success (arguments of opposite) of the UNO. When liberalists declare UNO as an 'effective institute', they leave out essential weaknesses of the UNO that are fundamental and real as pointed by the realists. Identically, when realists declare UNO as an 'ineffective institute', they leave out essential achievements and successes of the UNO as identified by the liberalists. Therefore, the explanations offered by both liberalists and realists are inadequate and therefore misleading to the overall evaluation of the effectiveness of the UNO. This marks serious limits of the explanations offered by these theories to the evaluation of the overall effectiveness of the UNO.

\section{Evaluating the Effectiveness of the UNO: A 'New Analytical Framework:-}

Given the limits of the theories in evaluating the effectiveness of UNO in the backdrop, it is time for developing a 'new analytical framework' for a better evaluation of the effectiveness of the UNO. This essay proposes a new analytical framework to the evaluation of the effectiveness of the UNO that is an 'issue specific' or 'case specific' analytical framework for evaluating the effectiveness of the UNO. The New Framework suggests evaluating particular case or issue and whether the UNO is successful or unsuccessful, whether realist power politics played dominant role over liberalist thought or the liberalist principals triumph over realist interpretation. Whether the leaders failed to reach a better decision making or succeed to reach a better decision making with regard to specific issue like preserving international peace and security, international health, and promoting human rights worldwide etc. or specific case like crisis in any state or region, prioritizing any event that deserve international attention and taking appropriate steps etc.

There is no doubt that the UNO has provided a common platform that facilitates communication among all memberstates, of all ideologies throughout the world. Member-states are allowed to broach issues of concerns, for discussion and necessary action. Each state has opportunity to represent their opinion. Appropriately some scholars argue that UNO should not only be regarded as an institution used for peacekeeping, but also as a tool to get to know and understand different communities and cultures; a medium for exchange which will ultimately promote world peace. This new approach based analysis will help to the better functioning of the UNO in the long-term because its issue or case specific assessment is likely to encourage better functioning of the UNO by pinpointing the causes of success and causes of failure regarding to specific case or issue and therefore encouraging or discouraging that. This will have impact on the future functioning of the UNO.

In sum, it would be seriously misleading to conclude that UNO is ineffective because of a number of aspects and just because of a number of cases of failures of the UNO. At the same time it would also be misleading to conclude UNO is wholly effective institute despite its serious limitations. Therefore, the analysis of the UNO's effectiveness should be case or issue specific.

\section{Epilogue:-}

UNO has been the most successful international organization in the history of the world. Though UNO is not a perfect institution, it has flaws, before concluding it as an ineffective institute it is necessary to take into consideration the success stories of the UNO throughout the world. Any explanation should not elude any fundamental aspect that is essential and authentic. Beyond the argument that UNO to be effective or ineffective institution the truth is despite the member states' differences on cultural, political and economic grounds, "there are certain common purposes and principles which have wide popular appeal and which governments accept as being not only morally good but also as conforming to the best interests of their respective peoples" (Goodrich 1974:27). Grieco noted, "...even if the realists are correct in believing that anarchy constrains the willingness of states to cooperate, states nevertheless can work together and can do so especially with the assistance of international institutions" (Grieco, 1988:3).

The UNO has emerged as the key mechanism to the world governance. Kay noted that "...it is almost impossible for one country to insulate itself from the rest of the world and to pursue policies, whether economic, social or military, that can be said to be solely in their own national self-interest" (Kay, 1977:9). UNO has created the most accepted 
common platform for the leaders of the world that facilitates dialogue between and among the states of the world. Leaders of the world can discuss and take initiative to undertake appropriate steps for solving world problems. As the time goes by and newer problems unfold the leaders of the world can take appropriate steps by revising and updating the UNO for a better world. The construction of a better UNO is the key to the creation of a better future world.

When an analysis is undertaken to understand what a particular school of thought says about the effectiveness of the UNO is one thing but when an analysis is undertaken to evaluate the effective of the UNO, it is essential to take this 'new approach', case or issue specific approach, into consideration going beyond the traditional theoretical interpretations because this 'new approach' based analysis gives more effective, rigorous and pragmatic explanation about the effectiveness of the UNO.

\section{References:-}

1. Baylis, John \& Smith, Steve \& Owens, Patricia (2011). The Globalization of World Politics: An introduction to international relations $5^{\text {th }}$ edition. New York, Oxford University Press

2. Burchill, S., et al. (2005). Theories of International Relations. $3^{\text {rd }} \mathrm{ed}$. London: Palgrave Macmillan., pp. 150.

3. Dunne, Tim \& Kurki, Milja \& Smith, Steve (2010). International Relations Theories: Discipline and Diversity $2^{\text {nd }}$ edition. New York, Oxford University Press.

4. Forsyth, Kim (2001) Critical realism and political ecology. London, Athlone Press.

5. Grieco, J. M. (1988). Anarchy and the Limits of Cooperation: A Realist Critique of the Newest Liberal Institutionalism, International Organization, 42(3).

6. Goodrich, Leland (1974), The United Nations in a changing world, New York:Columbia University Press.

7. Hanhimäki, J. M., (2008) The United Nations: A very short introduction. New York: Oxford University Press., pp. 1.

8. Kay, D. A., (1977) The Changing United Nations, Options for the United States, New York: Praeger Special Studies., pp. 3-9

9. Kant, Immanuel (1970): Political Writings in Reiss, H.S. (edited) London, University of Cambridge Press

10. Mearsheimer, J. J. (1994). The False Promise of International Institutions. International Security, 19 (3), pp. 13.

11. Rittberger, Volker \& Zangl, Bernhard (2006) International Organization: Polity, Politics and Policies. New York, Palgrave Macmillan.

12. Russett, Bruce (2010) "Liberalism" in Dunne, Tim, Kurki, Milja and Smith, Steve (eds) International Relations Theories - Discipline and diversity, New York:Oxford University Press.

13. Thakur, Ramesh (ed) (1998), Past Imperfect, Future Uncertain, Basingtoke:The Macmillan Press Ltd

14. The Economist, (2012). Leaky Sieve; How world institutions were built. [online] The Economist Newspaper Limited, Available at: http://economist.come/node/21563273, (Accessed 11 November 2012).

15. The Kantian Project in International Relations: "The earliest theory of globalisation" (2003) http://asrudiancenter.wordpress.com/2011/02/22/the-kantian-project-in-international-relations-the-earliesttheory-of-globalisation/, Date Accessed: 15/11/2012

16. United Nations Environmental Programme (2012) "Environment for development" http://www.un.org/en/globalissues/women/, Date Accessed: 17/11/2012

17. Weiss, Thomas \& Forsythe, David \& Coate, Roger \& Pease, Kelly-Kate (2007): The United Nations and Changing World Politics $5^{\text {th }}$ edition. Colorado, Westview Press.

18. World Health Organisation "Criticisms Profile: of the WHO" (2008) http://tlc.howstuffworks.com/family/who5.htm, Date Accessed: 14/11/2012

19. Zaman, Rashed Uz \& Biswas, Niloy Ranjan (2014): Bangladesh's Participation in UN Peacekeeping Missions and Challenges for Civil-Military Relations: A Case for Concordance Theory, International Peacekeeping. 